\title{
lattva
}

JOURNAL OF PHILOSOPHY

\section{ARISTOTELIAN EFFICIENCY AND ITS DETERMINATE POSSIBILITIES FOR PROCESS ONTOLOGY}

\author{
Megan Altman
}

\begin{abstract}
:
In this paper I will contest the neglect of Aristotle's efficient cause as this denial is found in Campbell and Rescher's descriptions of process metaphysics. With this pursuit in mind I will inquire into the respective potentiality-actuality (PA) ontological frameworks of process metaphysics and Aristotle's metaphysics, which will include a discussion of the ontological implications of efficient causality in terms of action. After both accounts have been presented I will briefly discuss their similarities, and will then inquire into their differences. Herein I will place an emphasis on the differences between Aristotle's concerns for efficacy and process metaphysicians' reliance on teleology. I hope this PA analysis brings forth how Rescher and Campbell's' descriptions of process ontology do not contain a thoroughly developed PA scheme that allows for their avoidance of deeply rooted traditional metaphysical difficulties.
\end{abstract}

Henceforth, when I mention process ontology and process metaphysics I am referring to the work of Campbell and Rescher. 
Process metaphysicians, Nicholas Rescher and Richard Campbell, claim that the processes of ousia, i.e., individual beings, have ontological priority over the traditional Aristotelian concern with the matter and form of beings. Aristotle's metaphysical framework encompasses a hierarchy of the four causes: material (the matter from which a thing comes to be), formal (the form or pattern that the matter takes), efficient (the source of movement or change) and final (something's end or purpose). On the other hand, the framework for process metaphysics is primarily concerned with the final cause. ${ }^{2}$ Aristotle defines action in terms of its causal properties in his discussion of activity. ${ }^{3}$ Roughly stated, he distinguishes between incomplete activity, which only takes the final cause into consideration, and complete activity, which takes both efficient and final causes into consideration. Process ontology, according to Campbell, does incorporate Aristotle's teleological terminology of action in which an action is defined as such when the process is goal-oriented; however, process ontology attempts to define action only in terms of the felos. ${ }^{4}$ Accordingly, process metaphysics grants ontological priority to an action that is an incomplete activity. Furthermore, they believe that this priority is such a radicalization of traditional ontology that it dissolves "the problems of causation, of teleological purposiveness, and of mind-body interaction," which have plagued the tradition from the outset. ${ }^{5}$

\section{The Potentiality -Actuality Scheme in Substance Metaphysics}

Substance metaphysics can be historically traced back beyond Aristotle, but in this paper I will be concerned with the tradition following from Aristotle's substance ontology. For purposes of clarification it seems helpful to note the distinction between ontology and metaphysics, one might understand the difference as: the latter studies why and how what there is is while the former is concerned with what there-is. Metaphysics is a broader inquiry that encompasses ontology and other inquiries such as theology and cosmology. The grounding of Aristotle's ousia in his ontological framework must first be presented before an explanation of his PA scheme can be properly understood. Aristotle describes ousia as, "A substance [ousia] — that which

2 These definitions can be found in Aristotle. "Physics." Aristotle: Introductory Readings. Trans. Terence Irwin and Gail Fine. Hackett Publishing Company: Indianapolis, 1996. 36-68, 194b25-195a5. Throughout the rest of this paper Bekker numbers will be used when referring to Aristolle's works.

3 In the following Aristotle section I will explain the difference between action and activity.

4 Richard Campbell. The Emergence of Action (EA). In Press. (Section: "Goal-directedness").

5 Nicholas Rescher. Process Metaphysics. New York: State University of New York Press, 1996. 52. 
is called a substance most strictly, primarily, and most of all-is that which is neither said of a subject nor in a subject, e.g. the individual man or the individual horse." ${ }^{\prime 6}$ For Aristotle a primary substance cannot be predicated of nor analytically contained in the idea of a subject, and this is indicative of ousia as autonomous being. Furthermore, in Categories Aristotle writes, "It is distinctive of substance that numerically one and the same thing is able to receive contraries. ${ }^{17}$ This ability to receive contraries may seem a bit vague when not regarding Aristotle's other works, specifically Metaphysics and Nicomachean Ethics, in which ousiai are explained in terms of the efficient cause. Wolfgang-Rainer Mann, a contemporary scholar of ancient philosophy, discusses the implications of this link between ousia and its ability to receive contraries. Mann says,

The claim is obviously not that an ousia, e.g., Socrates, is both healthy and ill, or both pale and tan, at the same time. The claim rather is that an ousia can have one feature at one time, and an opposed feature at another, while remaining one and the same ousia. But that is just to say that ousiai can change whilst remaining the same; in other words, ousiai really can be subjects for change, because they can change their features. $^{8}$

Thus far an ousia can be identified as a thing, such as a rock, a nonhuman animal or a human being, because all three have the capacity to remain the same throughout changes. In Metaphysics Aristotle examines this capacity of a substance in terms of rational and nonrational potentiality, in which a thing and a nonhuman animal are differentiated from a human being. He explains the former contain nonrational potentiality due to the fact that they "act only in one way, "and a human being is defined as a rational potentiality from its ability to "act in contrary ways. ". Moreover, rational potentiality, e.g. thought, alone does not move anything or cause action, but rather "what moves us is thought aiming at some goal and concerned with action. ${ }^{\prime 10}$ I do not act without a purpose, but the addition of purpose alone is also not enough for action because the purpose in question must

- Aristotle. Categories and De Interpretatione. Trans. J.L. Ackrill. Clarendon Press: Oxford, 1963. 2a11.

7 Aristotle, 4 alo

8 Wolfgang-Rainer Mann. The Discovery of Things: Aristotle's Categories and Their Context. Princeton University Press: New Jersey, 2000. 202.

9 Aristotle, 1047b31-1048a20.

10 Aristotle. Nicomachean Ethics. Trans. Terence Irwin. $2^{\text {nd }}$ ed. Indianapolis: Hackket Publishing Comp., 1999. 1139b. 
include action. Thought and purpose alone are sufficient for bringing about action, because they do not explain the "why" or the cause of such movement. The principle of motion, i.e. the efficient cause, is my desire to achieve action or some other final cause. Action, as a telos, is explained in the Aristotelian ontology in terms of both efficient and final causation in which one cannot occur without the other.

Aristotle's typical method, the procedure that Mary-Lovise Gill, a contemporary Aristotle scholar, refers to as "instantiating on the focal meaning," is to look for the central application of the issue in question and explain the others with reference to that one. "It seems that the focal meaning can be understood as Aristotle's "central point." He points out the characteristics a "central point," saying, "There are many senses in which a thing may be said to 'be' but all that 'is' is related to one central point, one definite kind of thing, and is not said to 'be' by mere ambiguity. ${ }^{\prime 2}$ In other words, when looking at several things, finding what they most share in common and then relating each to that thing is the method of instantiating on the focal meaning. For instance, a lawyer, a client, a case, and a verdict are all called 'legal,' because that is what they all most have in common. Matter and form are explained in various ways throughout Aristotle's works. Gill discusses this issue, writing,

Many scholars think that in Metaphysics Aristotle awards the title 'primary substance' to form, revising the position he advocated in the Categories. [...] Others offer sophisticated readings of the chapter to show that form escapes the objections to the universal, even though it is predicated of matter. They argue that the chapter merely shows that nothing is the substance of that of which is universally predicated. Form is the substance of one thing, the composite, and predicated of something else, the matter. $^{13}$

Gill seems to be saying that the former side of the debate advocates for form as the universal ousia, while the latter side holds form as a particular that is predicated of the universal. However, I am not concerned with either side, because both refer to form and matter on the basis of the ousia. Matter and form, these causes are

"Mory Louise Gill. Aristotle on Substance: The Paradox of Unity. Princeton University Press: New Jersey, 1989. 173.

12 Aristotle. "Metaphysics." The Complete Works of Aristotle. Vol. 2. Ed. Jonathan Barnes. Princeton University Press: New Jersey, 1984. 1552-1728, 103a32-34.

13 Mary Louise Gill. "Aristotle's Distinction Between Change and Activity." Process Theories: Crossdisciplinary Studies in Dynamic Categories. Ed. Johanna Seibt. Kluwer Academic Publishers: Dordrecht, 2003, 5-6. 
attributes of potentiality and actuality, and one way of understanding these causes is to follow Aristotle's method of substantiating on the focal meaning, which in this case is potentiality and actuality. The purpose of this section is to understand Aristotle's doctrine of potentiality and actuality; therefore, potentiality and actuality are the focal meaning of matter and form.

In order to be able to grasp the distinction between potentiality and actuality a distinction between 'possibility' and 'impossibility' must be made, as John Watson, a late nineteenth century commentator on Aristotle, points out. Watson clearly expresses that "the potential must not be confused with mere possibility, i.e., with the possibility of anything whatever." Furthermore, according to Watson, "the only possibility that we can admit is the possibility of the actual." 14 I find it most fitting to begin by explaining potentiality without getting into actuality, because Watson's delimitation of potentiality against mere possibility is a crucial point. In Metaphysics Aristotle discusses change or capacity as the focal meaning of potentiality. In other words, that something has the capacity to be what it is does not necessitate that it will change, i.e, actually become what it is. An acorn has the capacity to become an oak tree. This capacity does not necessarily mean that it will actually become an oak tree, because, for example, a squirrel could eat the acorn or a person could smash it. Moreover, the acorn's capacity to become an oak tree is the central point or origin of its change, and the potentiality of the acorn is understood from this origin. Aristotle writes, "But all potentialities that conform to the same type are starting points, and are called potentialities in reference to one kind, which is a starting point of change in another thing or in the thing itself qua other, $[\ldots]$ i.e., by a principle of change. ${ }^{\prime 15}$ The potentiality of ousia, in regards to this passage, can be viewed as the arche (origin) and as such is a goal-directed projection toward the telos.

I have incorporated this teleological feature in the discussion of potentiality, because Aristotle uses the notion of capacity as the source of his principle of change. For the sake of brevity I will not discuss the particulars of capacity, but will use it to differentiate between potentiality and mere possibility. The former is more directed than the latter. In other words, in potentiality the ousia has something it is trying to attain, i.e., an end or a telos, but there is no direction or goal in mere possibility. For example, if I plan to mow the lawn today the possibility that the cloud could

14 John Watson. "The Metaphysic of Aristotle." The Philosophical Review 7.4 (1898): 337-354. 338. For Aristotle's discussion of possibility and mere possibility please refer to Metaphysics 1019b22-1020a6.

15

Metaphysics, 1046a9-15. 
form into the shape of a rabbit will not affect my ability to mow the lawn. But the cloud could potentially produce water-because it has the capacity to do so-and thus my activity of mowing the lawn will be impeded. Therefore it seems important to include Watson's characterization of potentiality as "determinate possibility", which he describes as, "the possibility of realization in a certain definite way." 16

What allows for the concreteness of potentiality, as a determinate possibility, is the understanding that what exists in potentiality is always existing towards an end or in pursuit of becoming what it will be. In potentiality the acorn is actively in the process of becoming an oak tree. The end, which is in this case being an oak tree, is the form of the potentiality of the acorn. The matter, i.e., the acorn stuff of the acorn and later the bark, leaves, roots, etc., here is that which is capable of being acted upon. ${ }^{17}$ Furthermore, the realization of the potentiality into actuality not only involves the form and matter but also necessitates material conditions. Watson describes the role of material conditions (in the potentiality of the acorn) when he writes, "the seed tends to develop into the plant, but it cannot do so without favorable soil, moisture, air and sunlight, which are its material conditions." has potential (becoming what it will be) to become actual (being what it is) when the matter is acted upon by itself and/or by the material conditions.

Though actuality is the telos of potentiality, it is not a complete end or action due to the fact that being is an ongoing activity or process. When the seed (as potentiality) passes into its actuality and becomes a plant, this end does not complete its life. For Aristotle there is a difference between the end as a felos and an end as a peras (limit). The telos is related to the 'goal' or purpose of an activity while the peras is more like a limit of the activity. The telos of an acorn is to become and to remain an oak tree but its existence, as an activity, has not reached its conclusion in actually becoming an oak tree, because its conclusion is only reached when it has perished (reached its limit). In actually being an oak tree it is actively existing as what it is. In other words, as an actual ousia it is in potentiality wherein it pursues being what it is as it is. Moreover, this process is divisible and continuous. Its

\footnotetext{
16 Wotson, 339.

1 Watson, 339.

13 Watson, 339. I do have a concern with the use of a material condition in relation to Aristolle's four causes, i.e., material, formal, efficient and final. In the case of the acorn the material cause seems to blur the function of the material and efficient cause the does claim that these causes often overlap). In this paper I am not concerned with Aristotle's PA scheme in relation to the four causes, but this noted confusion does suggest the need for further inquiry.
} 
divisibility comes from the fact that what is can be seen as it is in the 'now' moment. For instance, now I can be referred to as actually writing a paper with the potentiality of completing the paper, but this referential moment does not show anything about my past or future activities. However, this moment does imply that there was a past moment when I began writing, and there may be a future moment where I will stop writing. This double direction of the now moment, which links to the past and future, allows for the being in the PA process to be continuous. ${ }^{19}$ Traditionally, actuality has been interpreted as the end goal of potentiality, but this sense of completion does not allow for the eternal being found in Aristotle.

Now actuality viewed from this time-process perspective can be understood as eternal in the sense that its beginning cannot be known in a now-moment and its end cannot be foreseen. When 1 , as a human being, began existing cannot be known in terms of now. The beginning of my existence cannot be known from the fact that I exist now. And my exact end or death cannot be precisely known beforehand or within this now-moment. That is to say, my actions that account for (the movement of my actual existence suggest a twofold notion of being or ousia. For example, my activity or process of reading a book may suggest that I am a student-i.e., actual existence-that is actively attempting to acquire knowledgei.e., potential knowledge. This twofold description of the now-moment, which is my current process of reading a book, indicates that a process necessarily includes actuality and potentiality. By referencing the processes or ways that a human being is said to exist indicates a prior understanding of actual existence- 1 am a studentand of potential action-l am reading for the sake of gaining knowledge or being a better student. In other words, actuality is prior to potentiality in time, substance, and knowledge. ${ }^{20}$

Watson discusses the priority of actuality when he writes, "However far we carry back the process we never reach an unformed matter, but only that, which is matter relatively to the form which is expressed as actuality. ${ }^{121}$ Here Watson is referring to the fact that for Aristotle something cannot come from nothing, there is no ex nihilo; however, this does not mean that something must come from any specific thing. Rather, the process emerges from actuality only as it is in relation to potentiality. What occurs when potentiality and actuality coincide is a momentary action of the former transferred into the latter. This action, regarded'as emergence, is momentary

19 For more of the 'now' refer to Aristotle. "Physics." The Complete Works of Aristotle. Vol. 1. Ed. Jonathan Barnes. Princeton University Press: New Jersey, 1984, 222a10-222b29.

D Aristotle, Metaphysics, 1049b4-12; Watson, 340-343.

2) Watson, p. 340. 
due to the fact that actuality is not a complete end in itself, but rather is the beginning or origin of potentiality. Action as emergence, now understood as the moment when potentiality and actuality coincide in time, can be sufficiently described as an eternal activity - one that is for the sake of something else, because this is a complete activity and as such is continuous. ${ }^{22} \mathrm{~A}$ substance, i.e., ousia or being, is seen in time, and since time is eternal (continual) it follows that being is eternal. ${ }^{23}$ The ousia, which can now be understood as eternal being, is not a completed activity but is continuous and divisible energeia, i.e., actual activity.

Furthermore, Aristotle is concerned with the activity of human knowledge, or how we come to know that an entity is. He writes,

All men by nature desire to know. An indication of this is the delight we take in our senses; for even apart from their usefulness they are loved for themselves; and above all others the sense of sight. For not only with a view to action, but even when we are not going to do anything, we prefer sight to almost everything else. The reason is that this, most of all the senses, makes us know and brings to light many differences between things. ${ }^{24}$

According to this passage, human knowledge about what there is can be attained by seeing what it actually is. Potentiality, which has been explained as determinate possibility, presupposes actuality, because something can only be determinate in actuality. Moreover, the fact that an object can be seen could not have been known had no one ever seen it. ${ }^{25}$ So actuality must be prior to potentiality in time, substance and knowledge. In other words, knowledge of the now-moment, wherein potentiality transfers to actuality, only refers to a complete activity and not to actuality. To understand the implications of this statement it seems necessary to explain the Greek term associated with actuality, i.e., energeia.

As found in Aristotle there are two ways to understand energeia; the first is as an incomplete activity and the second is as a complete activity. Another way to express this is: a process, i.e., kinçsis, is an incomplete activity that is purely in potentiality,

2 It seems helpful to recall the distinction I posited earlier between an incomplete and a complete activity. The former only takes the final cause into consideration, which is to say that the action itself is the end. The latter, on the other hand, concerns both the efficient and final causes such that the activity is something for the sake of something else.

23 Watson, 344 .

24 Aristotle, Metaphysics, 980a25.

25 Watson, 340. 
and actuality is a complete activity that does not imply the loss of potentiality. In the case of the first kind of energeia the focus is on the potentiality wherein the object (what is) in question is potentially complete and actually incomplete. Gill explains this when she says, "The actuality in process [kinçsis] is incomplete. This actuality captures the object at all and only moments when it is potentially but not actually."26 Accordingly, the inquiry into this energeia is concerned with the kinçsis. Irwin interprets Aristotle's use of kinçsis when he states, "A kinçsis may be any difference in a thing's condition between two different times. Only something absolutely stable and invariant is exempt from kinçsis. "27 In other words, in kinçsis the object is actually incomplete in the sense that process or change is directed toward an end but is not an end in itself. The object here is potentially being, actually non-being and goal-directed. For Aristotle, this goal-directedness, or teleological element, pertains to the broad use of praxis, i.e., all intentional actions, and this is the action that process ontology relies on.

In the case of the second kind of energeia, which is complete activity, the object of inquiry is actually complete wherein "it is actively being what it is. "28 Imwin interprets the complete activity, or actual activity, when he states,

A complete activity does not imply the loss of the capacity that is actualized in the activity. Seeing or living, for instance, does not imply the loss of the capacity to see or live. A movement is incomplete because it aims at some end beyond itself whose achievement makes that movement impossible to continue, whereas a complete activity is its own end. ${ }^{29}$

From this interpretation it is sufficient to say that the object (what is) of inquiry here is actual being, i.e., ousia, because it is complete in itself as itself. Moreover, this being is identical with Aristotle's strict use of praxis, which is "a complete activity and not just a movement [kinçsis]." ${ }^{30}$ Suffice it to say that Aristotle's 'substance' ontology is concerned with the complete activity of being what it is, which is the energeia of the ousia.

26 Gill, 2003, 10.

z Aristotle. Nicomachean Ethics. $2^{\text {nd }}$ ed. Trans. Terence Irwin. Indianapolis: Hackett Publishing, 1999. 339. I would also like to note that Irwin translates kinçsis as process, change, movement and fluctuation.

2 Gill, 2003, 13 .

$2 \quad$ Aristotle, Nicomachean Ethics, p. 316.

o Aristotle, NE, 315. 


\section{The Potentiality-Actuality Scheme in Process Metaphysics}

In this section I will first lay out the doctrine of process metaphysics as explained by Richard Campbell and Nicholas Rescher. I will then follow Rescher's methodological procedure, which is to consider the issue in terms of what things do, in order to explain the PA scheme as found in process ontology. ${ }^{31}$ The discussion of this PA scheme will bring out the priority given to potentiality by process metaphysics. In looking at this priority I will examine how, according to process ontology, the preference of praxis (in the broadest sense: all intentional actions) over energeia (completed activity) is supposed to avoid the difficulties that have plagued the tradition. ${ }^{32}$

Rescher suggests that process metaphysics takes becoming and change as the central themes used to understand what things are "in the real." He describes becoming and change in these terms: "the origination, flourishing, and passing of the old and the innovative emergence of ever-new existence. ${ }^{\prime 33}$ From this description it seems that process metaphysics is concerned with the process of emergence, wherein the persistence of a process (or processes) is the focus of inquiry. Though process metaphysics stresses the phenomenon of change as the fundamental focus of inquiry, it does not disregard the relevance of substances. Rather, it gives priority to process over substance. Rescher discusses the reason for the priority of process, stating, "Processes are more fundamental than things [substances]. Since substantial things emerge in and from the world's course of changes, processes have priority over things. ${ }^{\prime 34}$ Moreover, the reliance on process, according to Rescher, stems from the belief that things are what they do and, as such, process ontology is grounded in understanding what it does.

Rescher claims that, for process metaphysics, the only satisfactory way to understand the existence of the things is to proceed in terms of what they do. ${ }^{35}$ Following this methodological procedure I will explain the PA scheme of process ontology, in

\footnotetext{
31 Rescher, 27.

3 Rescher, 52.

3 Rescher, 28.

34 Rescher, 28. Campbell speaks of this priority as a difference between process ontology and traditional ontology. He states, "That entities are not basic, but constituted, marks the crucial difference between our metaphysical model and that which has dominated Western philosophy since the time of the ancient Greeks." Please refer to Richard Campbell. A Process-Based Model for an Interactive Ontology (PBM). In Press. 7.

Rescher, 27.
} 
which potentiality seems to be explained in terms of emergence. ${ }^{36}$ Campbell defines emergence in its relation, or more specifically, its causal relation to a cohesive system. He describes this cohesive system as, "one in which its various internal processes work together to ensure that one of the forms of stability which it manifests is spatio-temporal integrity. ${ }^{137}$ The kinds of processes which are pertinent to process ontology are those whose stability persists throughout time and changes in their environment. Stability, according to Campbell, constitutes a cohesive system that can be identified and re-identified. A cohesive system is referred to as emergent when it is "produced by dynamical bonds that have non-aggregative, non-linear effects. "38 Campbell uses the expression "non-aggregative effects" to signify that some of the new causal powers cannot be mathematically understood as a sum of the parts of the whole, which is due to the fact that the causal powers of the new system do not refer to the "separate causal powers of its constituents." ${ }^{\text {"39 }}$ Campbell's "non-linear effects" pertain to the properties of the new system, which, like the new causal powers, cannot be explained by referring to the properties of the constituents of the new system, so these new properties are emergent. For example, sodium and chloride as separate, individual elements are poisonous when ingested. However, sodium and chloride together create salt. This is a complicated issue, but the general claim seems to be that the phenomenon of emergence, with its powers and properties, requires more than mathematical insight.

Process ontology is not concerned with what entities are in terms of Aristotelian actuality, but with what entities are in terms of its emergent properties and powers. Campbell claims that changes and new systems are no longer a mystery, writing, "Emergence should no longer be viewed as a dubious metaphysical mystery, but as explicable in terms of non-linear functions. ${ }^{.40}$ By setting aside concern for what a thing is that has actually emerged from the process of causation, metaphysics can now explain causation in terms of how it, as a process, functions, i.e., how it acts and what it does. These non-linear functions enable process metaphysics to explain ontology in terms of a "micro-to-macro" hierarchy. Campbell outlines this

3 I have made this terminological distinction based on the findings of my investigation of process ontology. Process ontology is solely concerned with emergence from potentiality and consequently disregards the phenomenon of actuality. Though this seems to be the case, 1 have not found a process ontology that explicitly defines or explains what potentiality is. This lack of terminological distinction may be due to the fact that they are concerned with what entities do rather than what they are.

3 Campbell, PBM, 7.

3 Campbell, 8.

3) Campbell, 8.

- Campbell, 8 . 
hierarchy when he says, "At the bottom is a level consisting of quantum fields, or whatever our best physics in the future tells us are the basic constituents out of which our world is generated. As we go up the levels, we successively encounter atoms, molecules, cells, multi-cellular organisms, human beings, social groups, institutions, etc. $^{\prime 41}$ Though the details of his hierarchy are interesting, for the purposes of this paper all that needs be understood is his view that the world can be explained in "processual" terms from bottom to top. Moreover, the emergence of causal powers consists in that the process, as a cohesive system, has contributed to its transformation into a new field with new properties. Such power of emergence is not in the process at the bottom of the hierarchy, because it requires cohesive systems that contribute to "the persistence of the conditions upon which they depend." 42

Campbell refers to self-maintenance systems as another way to express the contribution of a system required for an emergent causal power. He gives an example of a candle flame to explicate this when he writes,

The ability to be self-maintaining is an emergent causal power of the organization of the candle flame. Of course, in one sense its persistence is also dependent upon its external conditions: when the candle flame has burnt all its wax, or it is deprived of oxygen, it ceases to be. But so long as the boundary conditions are fulfilled - so long as its external requirements for fuel and oxygen continue to be satisfied - it continues to contribute to its own persistence. ${ }^{43}$

Furthermore, the ability of the flame to maintain its own process of burning cannot be explained in terms of a single causal property, because the system, as a process, is a holistic property as itself. The candle is non-autonomous, but the flame, as a process, has minimal autonomy. By this I mean that the emergent system is contingently autonomous due to the fact that the candle flame will perish when it is not provided with more wax or oxygen. In other words, the emergent flame is only one process - burning. Next there is a need to discuss the processes of the systems on the next hierarchical level, which Campbell terms as "recursively self-maintenance systems."

A discussion of recursively self-maintenance (RSM) systems will simultaneously lead to the beginning of an account of action in process ontology. RSM systems not only have the ability to maintain stability within certain ranges of conditions, but

4 Campbell, 9.

C Campbell, 10.

4 Campbell, 10. 
also "within certain ranges of changes of conditions." Campbell describes the dynamics of RSM systems when he says, "they can switch to deploying different processes depending on conditions they detect in their environment." As aforementioned, the candle flame does not have this ability, because it cannot provide itself with more wax or oxygen nor can it slow its burn rate, etc. RSM systems, according to Campbell, are able to maintain stability throughout the changes in their environmental conditions due to the fact that they can act appropriately in response to these changes. The autonomy Campbell grants to an RSM system is due to the maintenance of its own "internal activity," in which it is able to respond through action, to the flucluation of its environmental situation. He explains that "all biological organisms, from bacteria to humans," are RSM systems, because they can detect significant variations (significant in the sense that these changes could affect their stability) in their environmental conditions and can respond appropriately in order to maintain their autonomy. ${ }^{44}$ Before continuing I must point out that I am about to transition from explaining emergence, which is the potentiality contained in the framework of process ontology, to a discussion of action without mentioning actuality. This is because process ontology is not concerned with understanding the actual emergence, like Aristotle, as energeia, and prefers to examine the action of the emergent properties and powers.

In his graduated conception of action Campbell establishes three criteria for minimal action, and then builds upon this minimal action to explain 'stronger,' or more complex occurrences of action. In Campbell's account of process ontology the three criteria for minimal action are: goal-directedness, possibility of error, and "attributability" to the system as a whole. For the purpose of comparing the action in process ontology to the activity in 'substance' ontology l am only concerned with the goal-directedness criterion, as it differs from Aristotle's teleology. Campbell claims that action, as goal-directed, has a teleological structure in which the organism initiates its action and this action is aimed at a telos (end). The organism itself does the initiation, because, as a recursively self-maintenance system with internal activity, its action "cannot be imposed by an external organism." 45 On this account, the internal activity in simple bacteria is its metabolism and the metabolism's need for sugar is what initiates the bacteria's action. This is different from the action of a heat-seeking missile in which the "missile's target is programmed by the people who fired it, and its ways of adjusting its future movements have been built in by the manufacturers, not generated by itself." ${ }^{46}$ The target itself does not determine the behavior of the missile, because an external agent chose the target.

4 Campbell, $1-2,11$.

4 Campbell, 3.

46 Campbell, 3. 
Moreover, from the fact that the missile did not initiate its movement one is able to conclude that the target, which the missile is aiming at, is not internally related to the movement. According to Campbell, this behavior can only be explained in terms of movement and not action, because there is an important relation between action and its end. Campbell points out the difference between movement and action, stating,

A movement, or a series of movements, does not necessarily aim at anything. Both invoke change over time, but an action involves more than that. It is characteristic of an action-any action-that it intrinsically involves a telos, an objective towards which it directs its own movements. The structure of an action is essentially teleological. ${ }^{47}$

Though Campbell is using Aristotle's terminology he is "not trying to revive his entire metaphysical framework," because "that would be a serious mistake." One difference between their teleological structures is that Aristotle's framework involves the archç (origin or potentiality) projecting towards the telos, but in Campbell's framework the action is projecting towards the telos. In the Aristotelian account I am potentially writing a paper, and this activity is only an action when the paper is completed. The teleological structure in Campbell's account is only concerned with my action of writing a paper with the goal of completing it. Since process ontology is only concerned with describing a process in terms of what it is doing, there is no need to explain the origin or the completion of the action.

\section{The Lack of "Efficiency" in Process Ontology}

Process ontology may have dissolved the problems that have plagued traditional substance ontology, but Aristotle's concern with potentiality is not clearly identifiable with this tradition. Process ontology is concerned with the problem of emergence in substance ontology, so rather than beginning with an entity and trying to explain how it can act, they decide to begin with the act itself. Process philosophy is right to be concerned with the ontological significance of processes, and by granting priority to processes this ontological framework is able to "avert a whole list of avoidable philosophical difficulties." ${ }^{\prime 99}$ Moreover, process metaphysics is right to recognize Aristotle's commitment to processes. Rescher recognizes the importance of Aristotle's

4 Campbell, 4.

* Campbell, 4.

4 Rescher, 52. 
framework when he states, "The doctrine of causes, the role of activity and passivity among the categories, and emphasis on change in the theory of physics-all mark Aristotle as one of the key figures in the history of process philosophizing."

However, I am reluctant to accept Rescher's claim that process metaphysics simply reverses Aristotle's ontological framework. He describes this reversal, saying, "Aristotle's insistence on the primacy of substance and its ramifications [...] has proved to be decisive for much of Western philosophy. Process [ontology], however, has deliberately chosen to reverse this perspective. ${ }^{\prime \prime 0} \mathrm{It}$ seems that a true reversal of Aristotle's framework would necessitate an inclusion of actuality, because actuality, which has been explained as energeia, is an essential teleological component in his ontology. Aristotle is not merely concerned with actuality as itself, but rather he focuses on the energeia as it is intrinsically related to the telos. The Aristotelian framework can be mapped out like this: archç (potentiality) à telos (actuality). In this diagram the poteniality is projecting towards its actuality. The reversal of Aristotle's perspective, would have to look something like this: telos (actuality) à archç (potentiality), but this is not the framework of process ontology. Process ontology begins from action, which is internally related to the telos, and remains in action, so their framework could be mapped out thusly: à telos. In other words, process ontology disregards the teleological function in Aristolle's actuality and, therefore, does not reverse this framework. Process ontology simply reinterprets Aristotle sans actuality.

Furthermore, their dismissal of Aristotle's actuality seems to neglect an aspect of potentiality. For Aristotle there is no ex nihilo, which is to say that something cannot come from nothing and this is why potentiality is involved in actuality. As previously explained, the now-moment that occurs when potentiality transfers into actuality is understood as a momentary emergence of action. Emergence for Aristotle is action (praxis), as a completed activity, which consists of potentiality and actuality. In process ontology the completed action is not a necessary function in a processual world that only exists in potentiality. For their emergence to be compatible with Aristotle's emergence process ontology would have to take into account Aristotle's interpretation of an action, otherwise they seem to be talking about two completely different things. ${ }^{51}$

so Rescher, 29. I replaced 'metaphysics' with 'ontology' in this quote, because Resher does not make a distinction between the two. I have previously explained that they are not the same, so I switched the term to avoid confusion.

5) I would like to thank Adam Buben, Shawn Curtis, and Alex Levine for their helpful comments on earlier drafts of this paper. 


\section{Bibliography}

01) Aristotle. Categories and De Interprefatione. Trans. J.L. Ackrill. Clarendon Press: Oxford, 1963.

02) - "Metaphysics." The Complete Works of Aristotle. Vol. 2. Ed. Jonathan Barnes. Princeton University Press: New Jersey, 1984. 1552-1728.

03) -. Nicomachean Ethics. $2^{\text {nd }}$ ed. Trans. Terence Irwin. Indianapolis: Hackett Publishing, 1999.

04) - -. "Physics." Aristotle: Introductory Readings. Trans. Terence Irwin and Gail Fine. Hackett Publishing Company: Indianapolis, 1996. 36-68.

05) - "Physics." The Complete Works of Aristotle, Vol 1. Ed. Jonathan Barnes. Princeton University Press: New Jersey, 1984.

06) Campbell, Richard. A Process-Based Model for an Interactive Ontology. In Press.

07) --. The Emergence of Action. In Press. (Section: "Goal-directedness").

08) Graham, Daniel M. Explaining the Cosmos: The Ionian Tradition of Scientific Philosophy. Princeton: Princeton University Press, 2006.

09) Gill, Mary Louise. "Aristotle's Distinction Between Change and Activity." Process Theories: Crossdisciplinary Studies in Dynamic Categories. Ed. Johanna Seibt. Kluwer Academic Publishers: Dordrecht, 2003.

10) -. Aristotle on Substance: The Paradox of Unity, Princeton University Press: New Jersey, 1989.

11) Mann, Wolfgang-Rainer. The Discovery of Things: Aristotle's Categories and Their Context. Princeton University Press: New Jersey, 2000.

12) Rescher, Nicholas. Process Metaphysics. New York: State University of New York Press, 1996.

13) - Process Philosophy: A Suney of Basic Issues. Pittsburgh: University of Pittsburgh Press, 2000.

14) Watson, John. "The Metaphysic of Aristotle." The Philosophical Review 7.4 (1898): 337-354.

15) Whitehead, Alfred North. Process and Reality (Corrected Edition). Ed. David Ray Griffin and Donald W. Sherburne. New York: The Free Press. 1978. 